\title{
Two bio-inspired algorithms for solving optimal reactive power problem
}

\author{
Lenin Kanagasabai \\ Department of EEE, Prasad V. Potluri Siddhartha Institute of Technology, India
}

\begin{tabular}{|c|c|}
\hline Article Info & ABSTRACT \\
\hline Article history: & In this work two ground-breaking algorithms called; Sperm Motility (SM) \\
\hline Received Jan 3, 2020 & $\begin{array}{l}\text { algorithm \& Wolf Optimization (WO) algorithm is used for solving reactive } \\
\text { power problem. In sperm motility approach spontaneous movement of }\end{array}$ \\
\hline Revised Mar 4, 2020 & the sperm is imitated \& species chemo attractant, sperms are enthralled in \\
\hline Accepted Apr 25, 2020 & $\begin{array}{l}\text { the direction of the ovum. In wolf optimization algorithm the deeds of wolf is } \\
\text { imitated in the formulation \& it has a flag vector also length is equivalent to }\end{array}$ \\
\hline Keywords: & $\begin{array}{l}\text { the whole sum of numbers in the dataset the optimization. Both the projected } \\
\text { algorithms have been tested in standard IEEE } 57,118,300 \text { bus test systems. }\end{array}$ \\
\hline $\begin{array}{l}\text { Optimal reactive power } \\
\text { Sperm motility } \\
\text { Transmission loss }\end{array}$ & $\begin{array}{l}\text { Simulated outcomes reveal about the reduction of real power loss \& with } \\
\text { variables are in the standard limits. Almost both algorithms solved } \\
\text { the problem efficiently, yet wolf optimization has slight edge over the sperm } \\
\text { motility algorithm in reducing the real power loss. }\end{array}$ \\
\hline
\end{tabular}

This is an open access article under the CC BY-SA license.

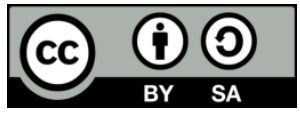

\section{Corresponding Author:}

Lenin Kanagasabai,

Department of EEE,

Prasad V. Potluri Siddhartha Institute of Technology,

Kanuru, Vijayawada, Andhra Pradesh-520007, India.

Email: gklenin@gmail.com

\section{INTRODUCTION}

Optimal reactive power problem has been key problem in power system, since it plays major role in secure \& economic operation of the power system. Many conventional methods [1-8] have been applied for solving optimal reactive power problem. But many drawbacks have been found in the conventional methods and mainly difficulty in handling the inequality constraints. Last two decades many evolutionary algorithms [9-18] continuously applied to solve the problem. This paper proposes a new Sperm Motility (SM) algorithm for solving optimal reactive power problem. Sperm Motility (SM) algorithm is stimulated by fertilization process in human beings [19]. Wolf optimization (WO) algorithm has been formulated on the basis of basic deeds of wolf search for the prey. The formulation has been enhanced by utilizing the velocity \& movement properties of particle swarm optimization algorithm.Both the projected algorithms have been tested in standard IEEE 57,118, 300 bus test systems. Simulated outcomes reveal about the reduction of real power loss \& with variables are in the standard limits. Almost both algorithms solved the problem efficiently, yet wolf optimization has slight edge over the sperm motility algorithm in reducing the real power loss.

\section{PROBLEM FORMULATION}

The key objective of the reactive power problem is to minimize the system real power loss \& given as, 


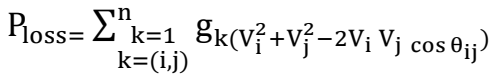

Voltage deviation magnitudes (VD) is stated as follows,

Minimize $\mathrm{VD}=\sum_{\mathrm{k}=1}^{\mathrm{nl}}\left|\mathrm{V}_{\mathrm{k}}-1.0\right|$

Load flow equality constraints:

$$
\begin{aligned}
& P_{G i}-P_{D i}-V_{i \sum_{j=1}^{n b} V_{j}}\left[\begin{array}{cc}
G_{i j} & \cos \theta_{i j} \\
+B_{i j} & \sin \theta_{i j}
\end{array}\right]=0, i=1,2 \ldots, n b \\
& Q_{G i}-Q_{D i}-V_{i \sum_{j=1}^{n b} v_{j}}\left[\begin{array}{cc}
G_{i j} & \sin \theta_{i j} \\
+B_{i j} & \cos \theta_{i j}
\end{array}\right]=0, i=1,2 \ldots, n b
\end{aligned}
$$

Inequality constraints are:

$$
\begin{aligned}
& V_{G i}^{\min } \leq V_{G i} \leq V_{G i}^{\max }, i \in n g \\
& V_{\mathrm{Li}}^{\min } \leq \mathrm{V}_{\mathrm{Li}} \leq \mathrm{V}_{\mathrm{Li}}^{\max }, \mathrm{i} \in \mathrm{nl} \\
& \mathrm{Q}_{\mathrm{Ci}}^{\min } \leq \mathrm{Q}_{\mathrm{Ci}} \leq \mathrm{Q}_{\mathrm{Ci}}^{\max }, \mathrm{i} \in \mathrm{nc} \\
& \mathrm{Q}_{\mathrm{Gi}}^{\min } \leq \mathrm{Q}_{\mathrm{Gi}} \leq \mathrm{Q}_{\mathrm{Gi}}^{\max }, \mathrm{i} \in \mathrm{ng} \\
& \mathrm{T}_{\mathrm{i}}^{\min } \leq \mathrm{T}_{\mathrm{i}} \leq \mathrm{T}_{\mathrm{i}}^{\max }, \mathrm{i} \in \mathrm{nt} \\
& \mathrm{S}_{\mathrm{Li}}^{\min } \leq \mathrm{S}_{\mathrm{Li}}^{\max }, \mathrm{i} \in \mathrm{nl}
\end{aligned}
$$

\section{SPERM MOTILITY ALGORITHM}

Sperm Motility (SM) algorithm has been inspired by the fertilization procedure in human beings. Throughout the exploration sequence as the species chemo attractant, sperms are fascinated towards the ovum. Also Chemo attractant \& concentration will induce the sperm when is moving closer to ovum. Utmost eminence sperm will be moved over \& expressed as -Type A. With probability $\mathrm{P}_{\mathrm{a}} \in[0,1]$ low quality sperms are discarded; specified as type B, C and D. Towards the ovum more than 220 million sperms swim capriciously with velocity $v_{i}$ at position $x_{i}, \&$ by the Stokes equations motility can be described as,

$$
R e=\left(\frac{\partial v}{\partial t}+v \cdot \nabla v\right)+\nabla p=\mu \nabla^{2} v+f \nabla \cdot v=0 x \in \Omega
$$

Simpler form of Stokes written as:

$$
\begin{aligned}
& \nabla p=\mu \nabla^{2} v+f \\
& \nabla . v=0, y \in \Omega
\end{aligned}
$$

C singularity velocity solution as follows,

$v_{i}(t)=\left(\frac{1}{8 \pi u}\right) *\left(\frac{\delta_{i j}}{h}+\frac{h_{i} h_{j}}{h^{3}}\right) * F l_{j}=\left(\frac{1}{8 \pi u}\right) * s_{i j}(y, \xi) * F l_{l j} ; i, j=1,2,3 \ldots$

Due to a force $F l_{j}$ concentrated at the point $\zeta$, the flow will be as,

$h_{i}=y-\xi$

$h^{2}=h_{1}^{2}+h_{2}^{2}+h_{3}^{2}$

It has been updated as,

$y_{i+1}(t)=y_{i}(t)+\left(\frac{\delta t}{2}\right) *\left(v_{i+1}(t)+v_{i}(t)\right)+\alpha\left(y_{i}(t)-J^{*}\right)$ 
Chemo attractant is defined as follows,

$$
c a_{i}(t)=c a_{o}(t)+c a_{1}\left(\left\|J^{*}-x_{i}(t)\right\|\right)^{-b}
$$

In current iteration $J^{*}$ is the outstanding solution exist.

Sperm Motility(SM) algorithm for solving reactive power problem

\section{Commence}

Based on the problem objective function is defined.

N sperm Population size is initialised

Primary attentiveness $\mathrm{c}_{0}$ has been engendered for $\mathrm{N}$ sperm with reference to primary position $\mathrm{y}_{0}$ and velocity $\mathrm{v}_{0}$ are produced.

Parameters of the motility are described; While ( $\mathrm{t}<$ Maximum Generation)

For $\mathrm{i}=1: \mathrm{N}$ do

Velocity $v_{i}$ is computed from By equation (14) using the data at $t=t_{i}$;

Position $\mathrm{x}_{\mathrm{i}}$ has been modernized for sperm $\mathrm{i}$, by equation (17)

Calculate the each sperm individual value, according to its position

When new solution is available \& superior then modernize the population.

Value of ca from equation (18) has been calculated.

When $c a_{i} \leq c a_{i-1}$, poorer sperm with help of $(\mathrm{Pa})$, will be abandon

Checking of the constraints with respective to objective function

End for

Existing outstanding population has been sorted out

End

\section{WOLF OPTIMIZATION}

Wolf optimization mimics the communal management and hunt deeds of wolf in nature [20]. There are three fittest candidate solutions assumed as $\alpha, \beta$ and $\gamma$ to lead the population toward promising regions of the exploration space in each iteration of wolf optimization. $\varphi$ is named for the rest of wolves and it will assist $\alpha, \beta$ and $\gamma$ to encircle, hunt, and attack prey, that is, to find Enriched solutions. In order to scientifically replicate the encompassing behavior of Red wolves, the following equations are proposed:

$$
\begin{aligned}
& \vec{G}=\left|\vec{F} \cdot \overrightarrow{Y_{P}}(t)-\vec{Y}(t)\right|, \\
& \vec{Y}(t+1)=\overrightarrow{Y_{P}}(t)-\vec{H} \cdot \vec{G}
\end{aligned}
$$

Where $t$ indicates the current iteration, $\overrightarrow{\mathrm{H}}=2 \overrightarrow{\mathrm{b}} \cdot \overrightarrow{\mathrm{r}_{1}}-\overrightarrow{\mathrm{b}}, \overrightarrow{\mathrm{F}}=2 \cdot \overrightarrow{\mathrm{r}_{2}}, \widehat{\mathrm{Y}_{\mathrm{P}}}$ the position vector of the prey, $\overrightarrow{\mathrm{Y}}$ is the position vector of a wolf, $\overrightarrow{\mathrm{b}}$ is linearly decreased from 2.0 to 0 , and $\overrightarrow{\mathrm{r}_{1}}$ and $\overrightarrow{\mathrm{r}_{2}}$ are arbitrary vectors in $[0,1]$. Hunting behavior of wolves are mathematically simulated by following equations,

$$
\begin{aligned}
& \overrightarrow{G_{\alpha}}=\left|\overrightarrow{F_{1}}, \overrightarrow{Y_{\alpha}}-\vec{Y}\right| \\
& \overrightarrow{G_{\beta}}=\left|\overrightarrow{F_{2}}, \overrightarrow{Y_{\beta}}-\vec{Y}\right| \\
& \overrightarrow{G_{\gamma}}=\left|\overrightarrow{F_{3}}, \overrightarrow{Y_{\gamma}}-\vec{Y}\right| \\
& \overrightarrow{Y_{1}}=\overrightarrow{Y_{\alpha}}-\overrightarrow{H_{1}} \cdot \overrightarrow{G_{\alpha}} \\
& \overrightarrow{Y_{2}}=\overrightarrow{Y_{\beta}}-\overrightarrow{H_{2}} \cdot \overrightarrow{G_{\beta}} \\
& \overrightarrow{Y_{3}}=\overrightarrow{Y_{\gamma}}-\overrightarrow{H_{3}} \cdot \overrightarrow{G_{\gamma}} \\
& \vec{Y}(t+1)=\frac{\overrightarrow{Y_{1}}+\overrightarrow{Y_{2}}+\overrightarrow{Y_{3}}}{3}
\end{aligned}
$$

Position of wolf was updated by (19) \& the following equation is used to discrete the position.

$$
\text { flag }_{i, j}= \begin{cases}1 & Y_{i, j}>0.50 \\ 0 & \text { otherwise }\end{cases}
$$


Where $\mathrm{i}$, indicates the jth position of the ith wolf, flag $_{i, j}$ is features of the wolf.

To enhance the search velocity \& position updating equations form particle swarm optimization has been incorporated in this approach.

$$
\begin{aligned}
& v_{t+1}^{i}=\omega_{t} \cdot v_{t}^{i}+c g_{1} \cdot R m_{1} \cdot\left(m_{t}^{i}-y_{t}^{i}\right)+c g_{2} \cdot R m_{2} \cdot\left(m_{t}^{g}-y_{t}^{i}\right) \\
& y_{t+1}^{i}=y_{t}^{i}+v_{t+1}^{i}
\end{aligned}
$$

The current position of particle is $y_{t}^{i} \&$ search velocity is $v_{t}^{i}$. Global best-found position is. $m_{t}^{g}$. In uniformly distributed interval $(0,1) \mathrm{Rm}_{1} \& \mathrm{Rm}_{2}$ are arbitrary numbers. Where $\mathrm{cg}_{1}$ and $\mathrm{cg}_{2}$ are scaling parameters. $\omega_{\mathrm{t}}$ is the particle inertia. The variable $\omega_{\mathrm{t}}$ is modernized as

$$
\omega_{t}=\left(\omega_{\max }-\omega_{\min }\right) \cdot \frac{\left(t_{\max }-t\right)}{t_{\max }}+\omega_{\min }
$$

Maximum and minimum of $\omega_{\mathrm{t}}$ is represented by $\omega_{\max }$ and $\omega_{\min }$; maximum number of iterations is given by $t_{\max }$. Until termination conditions are met this process will be repeated. In this approach wolves categorized as $\alpha, \beta$ and $\gamma$ determine the position of the prey. $\vec{H}=2 \overrightarrow{\mathrm{b}} \cdot \overrightarrow{\mathrm{r}_{1}}-\overrightarrow{\mathrm{b}}$ directs the exploration \& exploitation process by reducing the value from 2 to 0 . When $|\overrightarrow{\mathrm{H}}|<1$ it converged towards the prey \& If $|\overrightarrow{\mathrm{H}}|>1$ diverged away. The first best Minimum loss and variables are accumulated as " $\alpha$ " position, score \& as like second best, third best accumulated as " $\beta$ " and " $\gamma$ " position $\&$ score.

Commence

Initialize the parameters

Initialize $b, \vec{H}$ and $\vec{F}$; beginning positions of wolves has been stimulated.

$\mathrm{i}=1$ : population size

$\mathrm{j}=1: \mathrm{n}$

When $(i, j)>0.500$

(i) $=1$;

Else

(j) $=0$;

End if

End for

Work out the maximum fitness of wolves as follows,

Primary maximum fitness of the wolf is designated as " $\alpha$ "

Second maximum fitness of the wolf is designated as " $\beta$ "

Third maximum fitness of the wolf is designated as " $\gamma$ "

While $\mathrm{k}<$ maximum iteration

For $\mathrm{i}=1$ : population size

Exact Location of the existing wolf has been revised periodically

End for

For $\mathrm{i}=1$ : population size

For $i=1: n ;$ If $(i, j)>0.496$

(j) $=1$;

Else

$(\mathrm{j})=0$;

End if

End for

Sporadically revise the values of $\mathrm{b}, \overrightarrow{\mathrm{H}}$ and $\overrightarrow{\mathrm{F}}$;

At this stage Fitness of wolves has been calculated

The assessment of wolves " $\alpha$ ", $\beta$ " and " $\gamma$ " has to be revised

$\mathrm{k}=\mathrm{k}+1$;

End while

Re-examine the value of" $\alpha$ "as the optimal characteristic division;

End

\section{SIMULATED OUTCOME}

At first IEEE 57 bus system [21] is used as test system to validate the performance of the proposed algorithms. Total active and reactive power demands in the system are 1240.68 MW and 330.82 MVAR, 
respectively. Generator data the system is given in Table 1. The optimum loss comparison is presented in Table 2. Number of iterations taken is $32 \&$ time taken $11.24 \mathrm{sec}$.

Table 1. Generator data

\begin{tabular}{ccccc}
\hline Generator No & Pgi minimum & Pgi maximum & Qgi minimum & Qgi maximum \\
\hline 1 & 25.00 & 50.00 & 0.00 & 0.00 \\
2 & 15.00 & 90.00 & -17.00 & 50.00 \\
3 & 10.00 & 500.00 & -10.00 & 60.00 \\
4 & 10.00 & 50.00 & -8.00 & 25.00 \\
5 & 12.00 & 50.00 & -140.00 & 200.00 \\
6 & 10.00 & 360.00 & -3.00 & 9.00 \\
7 & 50.00 & 550.00 & -50.00 & 155.00 \\
\hline
\end{tabular}

Table 2 comparison of losses

\begin{tabular}{|c|c|c|c|c|c|c|c|c|c|}
\hline Parameter & $\begin{array}{l}\text { Method } \\
\text { CLPSO } \\
{[22]}\end{array}$ & $\begin{array}{l}\text { Method } \\
\text { DE } \\
{[23]}\end{array}$ & $\begin{array}{l}\text { Method } \\
\text { GSA } \\
{[23]}\end{array}$ & $\begin{array}{l}\text { Method } \\
\text { OGSA } \\
{[24]}\end{array}$ & $\begin{array}{l}\text { Method } \\
\text { SOA } \\
{[22]}\end{array}$ & $\begin{array}{l}\text { Method } \\
\text { QODE } \\
{[23]}\end{array}$ & $\begin{array}{l}\text { Method } \\
\text { CSA } \\
{[25]}\end{array}$ & SM & WO \\
\hline $\begin{array}{l}\text { PLOSS } \\
\text { (MW) }\end{array}$ & 24.5152 & 16.7857 & 23.4611 & 23.43 & 24.2654 & 15.8473 & 15.5149 & 12.1482 & 12.0064 \\
\hline
\end{tabular}

Secondly IEEE 118 bus system [26] is used as test system to validate the performance of the proposed algorithms. Table 3 shows limit values and Table 4 show the comparison of results.

Table 3. Limitation of reactive power sources

\begin{tabular}{cccccccc}
\hline Bus number & 5 & 34 & 37 & 44 & 45 & 46 & 48 \\
\hline Maximum value of QC & 0.000 & 14.000 & 0.000 & 10.000 & 10.000 & 10.000 & 15.000 \\
Minimum value of QC & -40.000 & 0.000 & -25.000 & 0.000 & 0.000 & 0.000 & 0.000 \\
Bus number & 74 & 79 & 82 & 83 & 105 & 107 & 110 \\
Maximum value of QC & 12.000 & 20.000 & 20.000 & 10.000 & 20.000 & 6.000 & 6.000 \\
Minimum value of QC & 0.000 & 0.000 & 0.000 & 0.000 & 0.000 & 0.000 & 0.000 \\
\hline
\end{tabular}

Table 4. Evaluation of results

\begin{tabular}{|c|c|c|c|c|c|}
\hline $\begin{array}{c}\text { Active power loss - Minimum \& } \\
\text { Maximum values }\end{array}$ & $\begin{array}{c}\text { Methodology - } \\
\text { BBO } \\
{[27]}\end{array}$ & $\begin{array}{c}\text { Methodology - } \\
\text { ILSBBO/ } \\
\text { strategy1 } \\
{[27]}\end{array}$ & $\begin{array}{c}\text { Methodology } \\
\text { ILSBBO/ } \\
\text { strategy1 } \\
{[27]}\end{array}$ & SM & WO \\
\hline Minimum value & 128.770 & 126.980 & 124.780 & 126.540 & 125.172 \\
\hline Maximum value & 132.640 & 137.340 & 132.390 & 132.860 & 131.248 \\
\hline Average value & 130.210 & 130.370 & 129.220 & 129.120 & 128.864 \\
\hline
\end{tabular}

Finally IEEE 300 bus system [21] is used as test system to validate the performance of the proposed algorithms. Table 5 shows the comparison of real power loss obtained after optimization.

Table 5 comparison of real power loss

\begin{tabular}{llllll}
\hline Parameter & Method EGA [28] & Method EEA [28] & Method CSA [25] & SM & WO \\
\hline PLOSS (MW) & 646.2998 & 650.6027 & 635.8942 & 630.1898 & 629.2824 \\
\hline
\end{tabular}

\section{CONCLUSION}

In this paper both Sperm Motility (SM) algorithm \& Wolf Optimization (WO) algorithm solved the problem successfully. Performance of both above said algorithms in solving the problem is outstanding. Both the projected algorithms have been tested in standard IEEE 57,118, 300 bus test systems. Simulated outcomes reveal about the reduction of real power loss \& with variables are in the standard limits. Almost both algorithms solved the problem efficiently, yet wolf optimization has slight edge over the sperm motility algorithm in reducing the real power loss.

\section{REFERENCES}

[1] K. Y. Lee, "Fuel-cost minimisation for both real and reactive-power dispatches," Proceedings Generation, Transmission and Distribution Conference, vol. 131, no. 3, pp. 85-93, 1984. 
[2] N. I. Deeb, "An efficient technique for reactive power dispatch using a revised linear programming approach," Electric Power System Research, vol. 15, no. 2, pp. 121-134, 1988.

[3] M. R. Bjelogrlic, M. S. Calovic, B. S. Babic, et. al., "Application of Newton's optimal power flow in voltage/reactive power control," IEEE Trans Power System, vol. 5, no. 4, pp. 1447-1454, 1990.

[4] S. Granville, "Optimal reactive dispatch through interior point methods," IEEE Transactions on Power System, vol. 9, no. 1, pp. 136-146, 1994.

[5] N. Grudinin, "Reactive power optimization using successive quadratic programming method," IEEE Transactions on Power System, vol. 13, no. 4, pp. 1219-1225, 1998.

[6] Wei Yan, J. Yu, D. C. Yu and K. Bhattarai, "A new optimal reactive power flow model in rectangular form and its solution by predictor corrector primal dual interior point method," IEEE Trans. Pwr. Syst.,vol. 21, no.1, pp. 61-67, 2006.

[7] Aparajita Mukherjee, Vivekananda Mukherjee, "Solution of optimal reactive power dispatch by chaotic krill herd algorithm," IET Gener. Transm. Distrib, , Vol. 9, no. 15, pp. 2351-2362, 2015.

[8] Hu, Z., Wang, X. \& Taylor, G. Stochastic optimal reactive power dispatch: Formulation and solution method. Electr. Power Energy Syst., vol. 32, pp. 615-621. 2010.

[9] Mahaletchumi A/P Morgan , Nor Rul Hasma Abdullah, Mohd Herwan Sulaiman, Mahfuzah Mustafa and Rosdiyana Samad, "Computational intelligence technique for static VAR compensator (SVC) installation considering multi-contingencies (N-m)," ARPN Journal of Engineering and Applied Sciences, vol. 10, no. 22,2015 .

[10] Mohd Herwan Sulaiman, Zuriani Mustaffa, Hamdan Daniyal, Mohd Rusllim Mohamed and Omar Aliman, "Solving Optimal Reactive Power Planning Problem Utilizing Nature Inspired Computing Techniques," ARPN Journal of Engineering and Applied Sciences, vol. 10, no. 21, pp. 9779-9785. 2015.

[11] Mohd Herwan Sulaiman, Wong Lo Ing, Zuriani Mustaffa and Mohd Rusllim Mohamed, "Grey Wolf Optimizer for Solving Economic Dispatch Problem with Valve-Loading Effects," ARPN Journal of Engineering and Applied Sciences, vol. 10, no. 21, pp. 9796-9801, 2015.

[12] Pandiarajan, K. \& Babulal, C. K. , "Fuzzy harmony search algorithm based optimal power flow for power system security enhancement," International Journal Electric Power Energy Syst., vol. 78, pp. 72-79. 2016.

[13] Mustaffa, Z., Sulaiman, M.H., Yusof, Y., Kamarulzaman, S.F., "A novel hybrid metaheuristic algorithm for short term load forecasting”, International Journal of Simulation: Systems, Science and Technology, vol. 17, no. 41, pp. 6.1-6.6. 2017.

[14] Sulaiman, M.H., Mustaffa, Z., Mohamed, M.R., Aliman, O., "An application of multi-verse optimizer for optimal reactive power dispatch problems," International Journal of Simulation: Systems, Science and Technology, vol. 17, no. 41, pp, 5.1-5.5. 2017.

[15] Mahaletchumi A/P Morgan, Nor Rul Hasma Abdullah, Mohd Herwan Sulaiman,Mahfuzah Mustafa and Rosdiyana Samad, "Multi-Objective Evolutionary Programming (MOEP) Using Mutation Based on Adaptive Mutation Operator (AMO) Applied For Optimal Reactive Power Dispatch," ARPN Journal of Engineering and Applied Sciences, vol. 11, no. 14, 2016.

[16] Rebecca Ng Shin Mei, Mohd Herwan Sulaiman, Zuriani Mustaffa, "Ant Lion Optimizer for Optimal Reactive Power Dispatch Solution,” Journal of Electrical Systems, "Special Issue AMPE2015", pp. 68-74. 2016.

[17] Mahaletchumi Morgan, Nor Rul Hasma Abdullah, Mohd Herwan Sulaiman, Mahfuzah Mustafa, Rosdiyana Samad, "Benchmark Studies on Optimal Reactive Power Dispatch (ORPD) Based Multi-objective Evolutionary Programming (MOEP) Using Mutation Based on Adaptive Mutation Adapter (AMO) and Polynomial Mutation Operator (PMO)," Journal of Electrical Systems, 2016.

[18] Rebecca Ng Shin Mei, Mohd Herwan Sulaiman, Zuriani Mustaffa, Hamdan Daniyal,"Optimal Reactive Power Dispatch Solution by Loss Minimization using Moth-Flame Optimization Technique," Applied Soft Computing, vol. 59, pp. 210-222, 2017.

[19] O. A. R. Ibrahim Hezam, "Sperm Motility Algorithm: A Novel Metaheuristic Approach for Global Optimization," Int. J. Oper. Res., vol. 28, no. 2, pp. 143-163, 2017.

[20] A. Kaveh and F. Shokohi, "Application of Grey Wolf Optimizer in design of castellated beams," Asian Journal of Civil Engineering, vol. 17, no. 5, pp. 683-700, 2016.

[21] .[Online] Available: http://www2.ee.washington.edu/research/pstca/

[22] C. Dai, et al., "Seeker optimization algorithm for optimal reactive power dispatch," IEEE Trans. Power Systems, vol. 24, no. 3, pp. 1218-1231, 2009.

[23] M. Basu, "Quasi-oppositional differential evolution for optimal reactive power dispatch," Electrical Power and Energy Systems, vol. 78, pp. 29-40, 2016.

[24] B. Shaw, et al., "Solution of reactive power dispatch of power systems by an opposition-based gravitational search algorithm," International Journal of Electrical Power Energy Systems, vol. 55, pp. 29-40, 2014.

[25] S. Surender Reddy, “Optimal Reactive Power Scheduling Using Cuckoo Search Algorithm,” International Journal of Electrical and Computer Engineering, Vol. 7, No. 5, pp. 2349-2356. 2017

[26] IEEE, "The IEEE 30-bus test system and the IEEE 118-test system," 1993, http://www.ee.washington.edu/trsearch/pstca/.

[27] Jiangtao Cao, Fuli Wang and Ping Li, "An Improved Biogeography-based Optimization Algorithm for Optimal Reactive Power Flow," International Journal of Control and Automation, vol.7, no.3, pp. 161-176, 2014.

[28] S.S. Reddy, et al., "Faster evolutionary algorithm based optimal power flow using incremental variables," Electrical Power and Energy Systems, vol. 54, pp. 198-210, 2014. 